\title{
Effects of task success or failure on causal attributions and person perception
}

\author{
CLYDE HENDRICK and MARTIN GIESEN \\ Kent State University, Kent, Ohio 44242
}

\begin{abstract}
An actor's outcome on a task (success-failure) was manipulated orthogonally to information that the actor either used or did not use drugs. Casual attributions for success-failure were obtained as well as trait ratings of the actor. Subjects read a case study of an artist who either succeeded or failed in his profession. For half of the subjects, the artist was described as using hard drugs, and no mention of drugs was made for the other half. It was predicted and confirmed that success-failure interacted with drugs-no drugs in determining attributions of ability. It was also found, as expected, that success was attributed to ability and motivation more than was failure. Further, success tended to be internally attributed to the actor, while failure was externally attributed. The interaction obtained for ability attribution was not obtained for a measure of trying, nor for the trait ratings. The results confirmed Kepka and Brickman's (1971) suggestion that ability and motivation are qualitatively different concepts in naive psychology, but some of their specific conclusions are questioned.
\end{abstract}

One important area of research stemming from Heider's (1958) analysis of naive psychology concerns the attributional process for achievement related behaviors. A substantial literature is concerned with the attributed causes for task success and failure (e.g., Feather \& Simon, 1971; Streufert \& Streufert, 1969; Weiner, 1972; Weiner, Frieze, Kukla, Reed, Rest, \& Rosenbaum, 1971; Weiner \& Kukla, 1970). One fairly well established generalization is that more motivation (trying) and ability (can) is attributed to a person who succeeds at a task than to one who fails (see Weiner, 1972, for a review).

The present experiment had three major objectives. (1) To examine the possible interactive effects of another variable in determining causal attributions for success-failure. Although stronger ability and motivational attributions are made for success than for failure, little is known about the various contextual conditions under which this relation holds. (2) Much of the relevant attributional research has used very abbreviated, almost skeletal, descriptions of the stimulus situations (e.g., McArthur, 1972; Weiner \& Kukla, 1970). This approach has the advantage of logical precision in variable manipulation, but sacrifices the realism of everyday conditions under which causal attributions are most often made. The present study advanced a step toward further realism by using a stimulus scenario of considerably greater complexity than has been typical. (3) Beyond simple attribution raltings (e.g., ability, effort, task difficulty, luck), most studies do not assess other attributions (e.g., traits) to the stimulus person. This lack is surprising in view of the large litcrature on impression formation in the Asch (1946) tradition. Recently, Kepka and Brickman (1971)

Reculests for reprints should be addressed to Clyde Hendrick, Devartment of Psvehology, Kent State University, Kent, Ohio 1.1212 found that in accordance with Heider's (1958) equation: Effect $=$ Ability $\times$ Motivation, attributed motivation decreased as ability increased. On this basis, Kepka and Brickman (1971, p. 226) argued that additive models of impression formation (Anderson, 1965) cannot account for the obtained results for motivation, which presumably is a "dynamic" construct differing from "structural" constructs such as ability or likability.

This conclusion is warranted only if it can be shown that trait attributions are sensitive in the same way and yield the same results as for manipulations of ability attribution. It may well be that trait attributions follow a different theoretical logic than that for attributions of ability and motivation. No relevant data exist pertaining to this issue. Therefore additional trait attributions as well as causal attributions for success-failure were of considerable interest in the present study.

There is some evidence that task success tends to be attributed to internal causes and failure to external causes (Streufert \& Streufert, 1969; Weiner, 1972). This result is consistent with the generalization of more ability attribution for success than for failure. In the present experiment, success-failure at a task was manipulated orthogonally to other information which served as a second variation in an external causal source. That additional information was whether a succeeding or failing actor either used or did not use drugs. Drugs such as alcohol, LSD, ete., have the unique property of being viewed as an external causal source which has been incorporated directly into the person's body.' Knowledge of drug use in conjunction with knowledge of task success or failure creates several inference problems for the attributor and leads to some interesting interaction predictions.

Consider a young artist who, at a showing of his work, is either a resounding success or failure. Based on past research, subjects should attribute more ability and 
motivation to the artist for success than for failure. However, failure should be attributed more strongly to such things as bad luck, foibles of the viewing public, etc. Now assume that extra information is given to the subjects that the artist uses drugs regularly. This added information must be combined in some way with knowledge of success-failure to arrive at causal ascription. Since drugs seem to be an external causal source, failure can be attributed to the drugs directly. There is an inference problem, however, since if drugs at least partially cause failure, the artist might succeed were he not taking drugs. Therefore, when the artist fails and takes drugs, he may be perceived as possessing more art ability than when he fails but does not take drugs. A comparable inference problem exists for success. Given success, drugs may be viewed as an external influence which falsely bolsters ability. To the extent that drugs contribute to success, pure ability does not. Therefore true art ability may be perceived as less when the artist takes drugs and succeeds than when he does not take drugs.

Similar reasoning applies in reverse to situational causal factors. For example, foibles of the viewing public should be perceived as a greater cause of failure when the artist does not take drugs, but success may be attributed more strongly to the viewing public when the artist takes drugs than when he does not take them.

In both instances noted above, the drug-no drug and success-failure manipulations should interact in determining causal attributions for succeeding and failing. In the experiment to be reported, subjects read a "case study" of an artist who either succeeded or failed in his endeavor. In order to test the interaction predictions, half of the subjects received information describing the artist as using drugs, and drugs were not mentioned to the remaining half of the subjects. Thus there were four experimental conditions constituting a 2 by 2 factorial design: success-drug, success-no drug, failure-drug, and failure-no drug. Subjects made ratings of causal attributions as well as trait ratings of the actor. No specific predictions were made for the trait ratings, although the results in comparison with the attribution ratings were of considerable interest.

It should be noted that the format of the present experiment followed the "postdiction" paradigm as defined by Weiner, 1972, p. 351, in his useful distinction of stages in the behavioral sequence. The experiment used a postdiction design in the sense that subjects began with an outcome (i.e., success or failure) which stimulated causal cognitions. On that basis, subjects could then experience affective responses to the situation and develop an expectancy for success for the artist on future tasks. In the present study, affective responses to the artist were measured by the trait ratings, and in addition a measure of perceived future success-failure was taken.

\section{METHOD}

\section{Overview}

Subjects participated in an experiment described as a study in social perception. They received a booklet entitled "Social Perception Case Study" which contained a two-page description of an actor in a situation and several pages of rating scales. Half of the subjects received booklets in which the actor succeeded in his endeavor, and the other half received booklets in which the actor failed. In addition, in half the booklets the actor was described as being on drugs, and no mention of drugs was made in the other half.

\section{Stimulus Booklets}

The first page of the booklet described the general nature of the task. It was indicated that the purpose of the project was to find out how people form impressions and opinions about social situations on the basis of verbal descriptions of the situations. The second page was constant for all conditions. It provided a brief history of John K. who graduated from college in 1965 with a major in art. The scenario indicated that John showed some talent for painting in college, and after graduation attended a professional art institute for one year. He then bummed around the country for a year in order to experience life more broadly. By July, 1967, John was broke and hungry, so he took a job in Chicago as a commercial artist, worked hard and saved his money. In August, 1968, John quit his job, and moved to New York, where he rented an "artist's pad," became acquainted with other would-be artists, and settled into a routine over the next 2 years of creative painting intermixed with free living.

The manipulations were introduced on the third page. For half the subjects there was no mention of drugs, but the other half received the following paragraph.

During college, John had occasionally smoked marijuana, and had tried "acid" once. When he joined the art colony in New York, he started using pot on a regular basis as was the custom among the artists. He also started using acid, only occasionally at first, but then more and more frequently. John always had "good trips," and he valued his heightened sensitivity to shapes and colors that resulted from the drug experience. He felt that the drug enhanced his artistic capabilities. In fact he often did paint during various stages of his drug experience, working very rapidly in the attempt to capture on canvas the sensations he subjectively experienced.

The next paragraph was a constant for all subjects.

From August, 1968 to late spring of 1970 John produced over 35 large paintings and numerous small ones. During this period he also acquired a "patron," the wife of a wealthy New York businessman. He met her at a party and they became friends. Although not technically expert in evaluating paintings, she "liked art" in general and admired John's work a great deal. During the spring of this year she persuaded John to have a "showing" of his work at her country estate. It was to be a big affair to which all of her society friends as well as several art critics were to be invited. The paintings were to be for sale, and the critics' judgments would probably be given in newspapers and on TV. John was receptive to the idea since his funds were exhausted, and besides, he felt he was ready to be recognized as a professional.

The success-failure manipulation was introduced in the last paragraph.

The exhibition was held in early July of this year. Great care was taken in arranging the paintings and in presenting them. A great many people came since John's friend and her husband 
Table 1

Summary F Ratios for Causal Attributions

\begin{tabular}{|c|c|c|c|c|c|c|}
\hline Source & df & $\begin{array}{c}\text { Success } \\
\text { so Far }\end{array}$ & $\begin{array}{l}\text { Success } \\
\text { in Future }\end{array}$ & $\begin{array}{c}\text { Art } \\
\text { Aólitity }\end{array}$ & Tried & $\begin{array}{c}\text { John } \\
\text { Himself }\end{array}$ \\
\hline A Success-Failure & 1 & $212.2^{* *}$ & $126.7 * *$ & $21.7^{* *}$ & $19.0 * *$ & .1 \\
\hline B Drug-No Drug & 1 & 3.5 & $20.6^{* *}$ & . & 2.1 & .2 \\
\hline C. Sex of Subjects & 1 & 1.2 & .4 & .0 & .0 & .8 \\
\hline$A$ by $B$ & 1 & .1 & $4.8^{*}$ & $6.4 * *$ & 1.9 & 2.5 \\
\hline A by C & 1 & .4 & 1.6 & 1.1 & $5.3 *$ & .7 \\
\hline $\mathrm{B}$ by $\mathrm{C}$ & 1 & .1 & .2 & .2 & .9 & .1 \\
\hline$A$ by $B$ by $C$ & 1 & 1.2 & .0 & .3 & .4 & 1.2 \\
\hline Error & 278 & $(4.03)$ & $(3.94)$ & $(1.69)$ & $(3.22)$ & $(4.15)$ \\
\hline Source & & $\begin{array}{l}\text { Life } \\
\text { Style }\end{array}$ & $\begin{array}{c}\text { Fads of } \\
\text { Public }\end{array}$ & Patron & $\begin{array}{l}\text { Chance } \\
\text { Factors }\end{array}$ & $\begin{array}{l}\text { Perceived } \\
\text { Similarity }\end{array}$ \\
\hline A Success-Failure & & .0 & 2.3 & $108.8 * *$ & 3.2 & .0 \\
\hline B Drug-No Drug & & .9 & .2 & .9 & .2 & $16.0^{* *}$ \\
\hline C Sex of Subjects & & .1 & 3.7 & .1 & 2.4 & $5.2 *$ \\
\hline A by $B$ & & $7.2^{* *}$ & $8.9 * *$ & 1.0 & 1.9 & .0 \\
\hline$A$ by $C$ & & .4 & .1 & .0 & .2 & .0 \\
\hline B by $C$ & & 2.9 & 1.5 & .0 & .0 & 1.8 \\
\hline$A$ by $B$ by $C$ & & 2.3 & .7 & .8 & $5.5 *$ & 2.5 \\
\hline Error & & $(3.08)$ & $(2.44)$ & $(4.36)$ & $(3.22)$ & $(3.70)$ \\
\hline
\end{tabular}

were influential people in New York society. The reactions of the people were uniformly (positive) (negative). The professional art critics were even more (positive) (negative). One said, ("I have never seen so much outstanding creativity in one set of paintings") ("I have never seen such an abominable set of trash masquerade under the pretense of serious art.") The sales figures were even more revealing. John (sold) (was unable to sell) (every) (a single) one of his paintings. The reactions of the nonexperts were probably best summarized by one of the woman's friends who said, "It is a dream, a fabulous dream") ("It is a bad dream, something out of a drunken nightmare.") All in all, the showing was a complete (success) (failure) for both John and his patron.

The ratings for the dependent variables followed the description of the story. These measures included 9 attribution questions, 15 trait ratings, and an item assessing perceived similarity between the subject and the artist. All ratings were made on a 9-point scale ranging from -4 to +4 with appropriate end labels (the items were rescored on a $1-9$ point basis for convenience in computation). The attribution items and some sample end labels were:

(1) How successful was John so far as an artist? (very unsuccessful - very successf ul)

(2) How likely is it that John will be very successful in the future as an artist? (highly unlikely - highly likely)

(3) How much art ability did John probably have? (low ability - high ability)

(4) How haro ulu Jonn try to succeed as an artist? (not at all-very hard)

(5) To what extent was John himself responsible for the outcome of his work at the exhibition?

(6) To what extent was John's style of life and behavior responsible for the outcome of his work at the exhibition?

(7) To what extent were the fads and fashions of the art public responsible for the outcome of John's work at the exhibition?

(8) To what extent was John's patron responsible for the outcome of his work at the exhibition?

(9) To what extent were chance factors responsible for the outcome of John's work at the exhibition?

The trait ratings tor John were: likable, self-centered, shrewd, naive, ambitious, perceptive, mature, mediocre, opportunist, warm, selt-disciplined, impulsive, responsible, idealistic, and out-of-touch. The end labels for the traits were "completely inappropriate" under -4 and "completely appropriate" under +4 . The similarity question was "How similar to yourself as a person would you say that John is?" In addition to these ratings, subjects were asked to describe in their own words what they thought was the major cause of John's (success) (failure).

\section{Subjects and Procedure}

Students from an introductory psychology course served in groups as subjects. The experiment was presented as a study in person perception, and the nature of the stimulus booklets was explained. The distribution of booklets was randomized within each group. The number of subjects per condition was: success-drug $(M=34, F=38)$, success-no $\operatorname{drug}(M=36, F=38)$, failure-drug $(M=43, F=29)$, and failure-no drug $(M=34$, $F=34$ )

\section{RESULTS}

The results are presented separately for the attribution ratings, trait ratings, and subjects' written comments.

\section{Attribution Ratings}

A 2 (success-failure) by 2 (drugs-no drugs) by 2 (male and female subjects) analysis of variance was performed on each of the nine attribution items and the similarity item. A summary of these analyses is shown in Table 1. The first item "How successful was John so far as an artist" was included as a check on the success-failure manipulation. The mean was 7.65 for the success condition and 4.13 for the failure condition $(F=212.2$, $p<.01$ ). None of the other effects were significant for this item.

Inspection of Table 1 indicates several significant main effects for success-failure. When John succeeded, he was attributed greater future success, more art ability, more trying, and the patron received more credit than when John failed. These results confirm past findings 

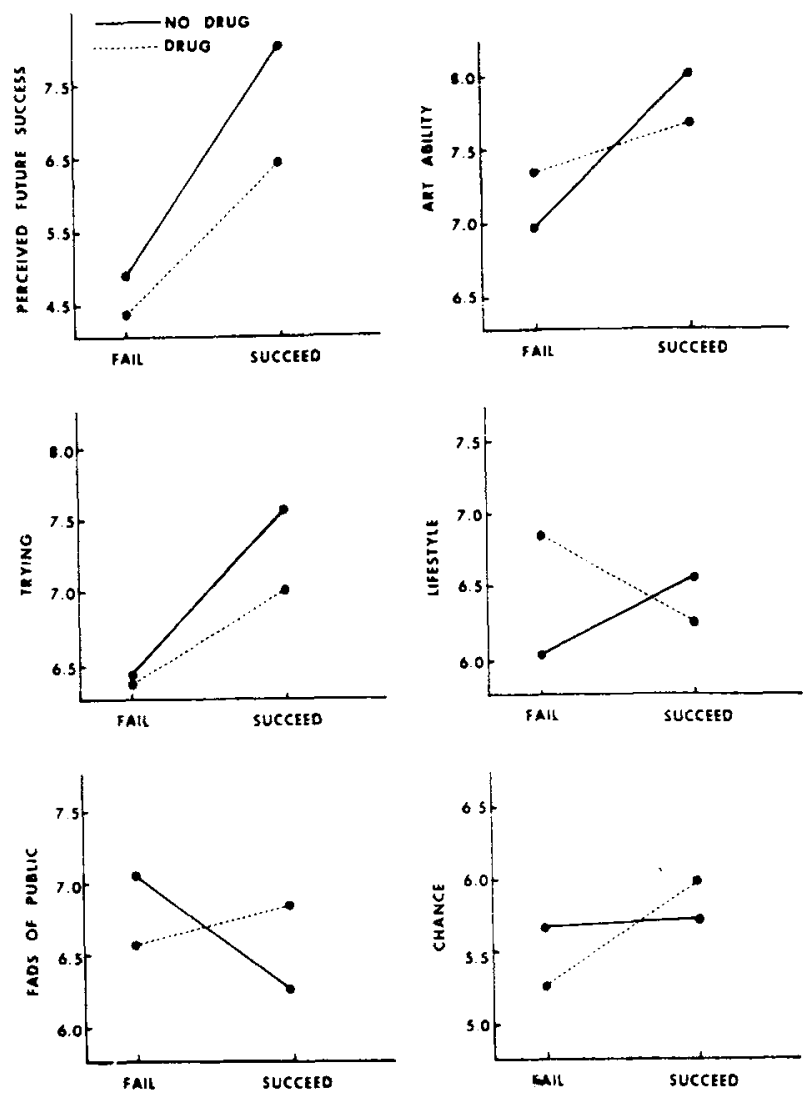

Figure 1. Causal attributions as a function of task success or failure, and drug usage or no drug usage.

that more positive attributions are made for success than for failure.

There were two main effects for the drug-no drug manipulation. John was rated higher on future success in the no drug (6.43) than in the drug (5.38) condition $(\mathrm{F}=20.6, \mathrm{p}<.01)$. Subjects in the no-drug condition rated themselves as more similar to John (4.50) than subjects in the drug (3.58) condition $(F=16.0, p<.01)$.

There were few effects due to sex of subjects. Quite reasonably, females rated themselves as less similar (3.75) to John than did male subjects $(4.33, F=5.2$, $\mathrm{p}<.05)$. Other than this main effect, sex of subjects entered into significant interaction terms only twice.

The important effect for testing the predictions was the Success by Drug $(A \times B)$ interactions. Table 1 indicates that this effect was significant for success in the future, art ability, John's life style, and fads of the public. The patterns of the means for these interactions are shown in Figure 1, as well as the means for trying and chance factors. The patterns of the means generally confirmed the predictions. More art ability was attributed to John when he succeeded without drugs than with them, but just the reverse was true when John failed. Greater future success was attributed when John succeeded without drugs than with them, but the drug variation made little difference when John failed. When
John succeeded, the drug-no drug variation had little effect on attributions to his life style. However, his life style received considerably more blame when John failed under drug than under no drug conditions. This pattern was reversed for fads of the viewing public. The public was blamed when John failed under no drugs but given credit when he succeeded with drugs. This result indicates clearly the preference to attribute success internally to qualities of the person, but to attribute failure externally to the environment.

The interaction for chance factors did not reach significance, apparently because of divergent results for males and females leading to a significant three-way interaction $(F=5.5, p<.05)$. For females there was a strong two-way interaction that had the form shown in Figure 1, but essentially no differences for males. Why such sex effects should occur for ratings of chance factors is unclear. Finally, the A by B interaction for trying was far from significant $(F=1.9)$. These results lend some support for Kepka and Brickman's (1971) contention that motivation is a different kind of construct. Ability (and related attributions) was sensitive to the drug manipulation, but trying was not, since only success-failure affected perceived trying (the effect of success-failure on trying was somewhat stronger for males than fermales, leading to the significant $\mathrm{A}$ by $\mathrm{C}$ effect shown in Table 1).

The rating of similarity was included because it was felt that the drug manipulation might affect subjects' perceived similarity to John. This was the case as noted earlier. However, the significant interactions shown in Figure 1 cannot be attributed in any way to variation in similarity because the $A$ by $B$ effect for perceived similarity was not sigificant $(F<1)$.

\section{Trait Ratings}

An analysis of variance was performed on each trait rating. A summary of these analyses is shown in Table 2 . Both the success-failure and drug-no drug manipulations had strong effects on trait attributions. Perhaps the most remarkable feature of Table 2 is the lack of significant interactions. Only 2 of 60 interaction effects were significant, about what would be expected by chance. The lack of significant A by B interactions for the trait ratings contrasts strongly with such interactions obtained for the attribution ratings.

There were significant differences due to success-failure on nine of the trait ratings. When John succeeded he was rated as more shrewd, less naive, more perceptive, more mature, less mediocre, more opportunistic, more self-disciplined, more responsible, and less out-of-touch than when he failed. These results indicate that success tended to create a positive attributional halo. On only one of the nine traits was John given a better rating in the failure than in the success condition (less opportunistic in the failure condition). 
Table 2

Summary F Ratios for Trait Ratings

\begin{tabular}{|c|c|c|c|c|c|c|c|c|}
\hline Source & $d f$ & Likable & Self-Centered & Shrewd & Naive & Ambitious & Perceptive & Mature \\
\hline A Success-Failure & 1 & .1 & .3 & $36.9 * *$ & $44.7^{* *}$ & 1.1 & $76.4^{* *}$ & $20.5 * *$ \\
\hline B Drug-No Drug & 1 & $5.4^{*}$ & .0 & .0 & .0 & $8.5^{* *}$ & 3.1 & $24.3^{* *}$ \\
\hline C Sex of Subjects & 1 & .8 & .3 & $4.0^{*}$ & $3.7 *$ & .0 & .0 & .0 \\
\hline$A$ by $B$ & $i$ & .2 & .1 & 2.0 & .7 & .0 & .2 & 6 \\
\hline $\mathrm{A}$ by $\mathrm{C}$ & $i$ & 3.0 & 1.1 & .1 & 1.1 & 2.9 & .1 & 1.9 \\
\hline B by $C$ & 1 & .5 & .0 & .3 & .1 & .1 & 3.1 & .0 \\
\hline$A$ by $B$ by $C$ & 1 & .1 & .4 & 1.2 & 1.0 & .1 & 3.7 & .8 \\
\hline Error & 278 & $(2.00)$ & $(4.45)$ & $(3.74)$ & $(4.17)$ & $(3.25)$ & $(3.28)$ & $(3.68)$ \\
\hline Source & Mediocre & $\begin{array}{l}\text { Opportu- } \\
\text { nistic }\end{array}$ & Warm & $\begin{array}{c}\text { Self- } \\
\text { Disciplined }\end{array}$ & Impulsive & $\begin{array}{c}\text { Respon- } \\
\text { sible }\end{array}$ & Idealistic & $\begin{array}{l}\text { Out of } \\
\text { Touch }\end{array}$ \\
\hline A Success-Failure & $9.2^{* *}$ & $9.7 * *$ & .5 & $12.8 * *$ & 2.6 & $18.3^{* *}$ & 1.3 & $17.1 * *$ \\
\hline B Drug-No Drug & .2 & $5.0^{*}$ & $7.2^{* *}$ & $43.6^{* *}$ & .2 & $24.5^{* *}$ & .0 & $9.9 * *$ \\
\hline C Sex of Subjects & .4 & .0 & .2 & .3 & .1 & .0 & .9 & .1 \\
\hline A by $B$ & 1.7 & $5.7^{*}$ & .6 & .3 & .0 & .2 & .7 & 1.6 \\
\hline A by $C$ & .9 & .3 & .6 & .8 & .6 & .7 & 2.7 & 1.1 \\
\hline B by $C$ & .1 & .2 & .0 & .0 & 3.1 & .1 & .0 & .0 \\
\hline$A$ by $B$ by $C$ & .2 & 3.6 & 2.1 & 1.6 & .0 & .2 & .5 & .2 \\
\hline Error & $(3.84)$ & $(3.48)$ & $(2.51)$ & $(5.01)$ & $(4.66)$ & $(3.81)$ & $(3.66)$ & $(3.96)$ \\
\hline
\end{tabular}

The drug manipulation had significant effects on eight of the trait ratings. John was rated higher in the no drug than in the drug condition on the traits likable, ambitious, mature, opportunist, warm, self-disciplined, and responsible. He was rated as more out-of-touch in the drug condition. The direction of the differences generally indicated a positive attribution bias in the no drug condition.

\section{Analysis of Written Comments}

Subjects were asked to describe in their own words what they thought was the major cause of John's success or failure. These comments were coded into categories. A summary of these results is given in Table 3 . Sexes were combined, since inspection of the data indicated there were no differences due to sex of subjects. A number of interesting patterns emerge from these data. In the two success conditions, subjects rather clearly attributed the success to John's ability ( $47 \%$ and $56 \%$ ), but failure was seldom attributed to lack of ability (6\% and $7 \%$ ). The difference between success and failure condition was highly significant $\left(\chi^{2}=67.4, p<.001\right)$. Also more subjects credited John's motivation or trying for his success (35\% and 31\%) than blamed lack of trying for failure $(15 \%$ and $11 \%)$. This difference was also significant $\left(\chi^{2}=10.7, p<.01\right)$. The cause for success was attributed to the patron more $(62 \%$ and $57 \%)$ than to responsibility for failure (12\% and $6 \%$ ). This difference was highly significant $\left(\chi^{2}=583.1\right.$, $p<.001)$. The experiential combination of school, travel, and the year in New York received more credit for John's success (35\% and 18\%) than was blamed for

Table 3

Summary of Written Comments

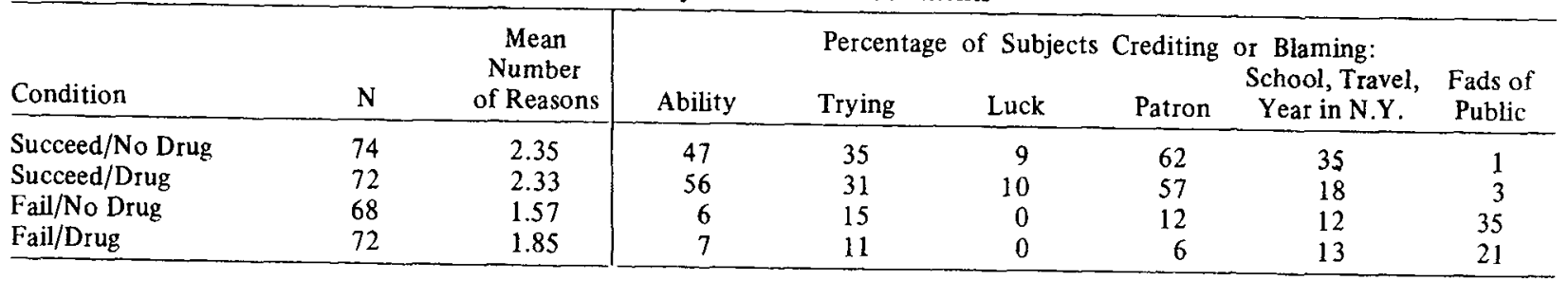

Percentage of Subjects Crediting or Blaming:

Drugs

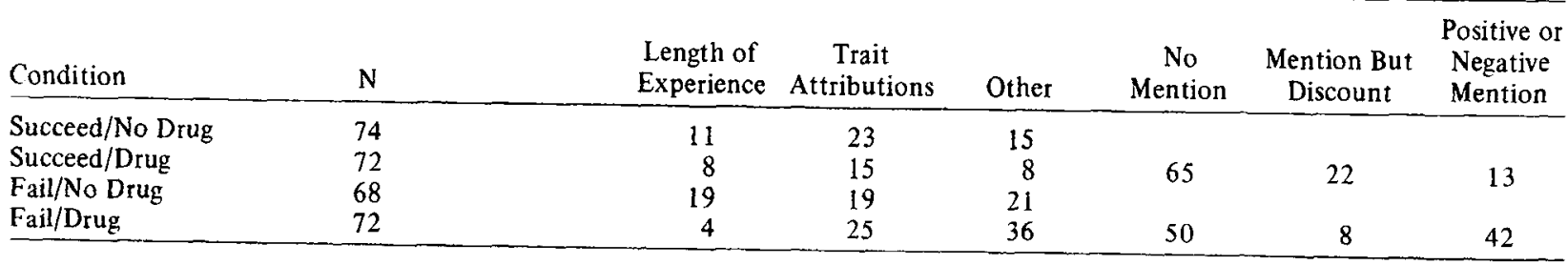


his failure $(12 \%$ and $13 \%)$. This difference was significant $\left(\chi^{2}=8.8, p<.01\right)$. Fads of the public were strongly blamed for John's failure (35\% and $21 \%$ ), but were not credited for his success (1\% and $3 \%$ ). This difference was significant $\left(\chi^{2}=5.4, \mathrm{p}<.02\right)$.

A residual category "other" was used for infrequent responses. Subjects in the failure conditions used a greater variety of other responses $(21 \%$ and $36 \%$ ) than subjects in the success conditions $(15 \%$ and $8 \%$ ). This difference was significant $\left(\chi^{2}=11.8, \mathrm{p}<.001\right)$. Thus, the variety of attributions was greater in the failure conditions in spite of the fact that the mean number of reasons given was smaller $(1.57$ and 1.85$)$ in the failure conditions than in the success conditions (2.35 and 2.33).

The results for the two drug conditions are of particular interest. In the drug-success condition, $65 \%$ of the subjects made no mention of drugs. Another $22 \%$ mentioned drugs but explicitly discounted the possibility that they were instrumental in John's success. Only $13 \%$ felt that drugs were a positive factor in John's success. In the drug-failure condition, $50 \%$ of the subjects made no mention of drugs, $8 \%$ mentioned them but discounted the possibility that they were responsible for failure, and $42 \%$ explicitly listed drugs as a reason for failure. Combining the no mention and discounting categories, the difference between success and failure conditions was highly significant $\left(\chi^{2}=14.0, p<.001\right)$.

To summarize, the written comments indicated that success was differentially attributed to ability, trying, the patron, and previous educational experience. Failure was attributed to fads of the public, drug usage, and a variety of "other" things. Success-failure did not affect attributions to luck, length of experience, or specific traits.

\section{DISCUSSION}

The data showed that even with a rather complex scenario, results followed predictions quite well and were generally in accord with results obtained by studies using very simple scenarios. Stronger ability and motivational attributions were made for success than for failure. Also, failure tended to be externally attributed while success was internally attributed. The drug manipulation interacted predictably with success-failure in determining ability and related attributions.

The analysis of subjects' written comments reinforced the conclusions stated above. Drugs were specifically blamed for John's failure, but a substantial number of subjects explicitly discounted the possibility that drugs might have caused John's success. More generally, the written comments confirmed overwhelmingly that success was attributed to internal factors (ability and trying) while failure was attributed to fads of the public. The results for the patron were interesting in that they followed the same pattern as for ability and trying. Very likely the patron was assimilated in subjects' cognitions by a kind of unit formation so that the patron essentially was perceived as an internal causal factor. This inference seems particularly likely because the story stated that the showing was a complete success (or failure) for both John and his patron.

The written comments suggest that failure was to some extent attributionally ambiguous in much the same way that a null hypothesis outcome is ambiguous. Subjects stated fewer reasons for failure than for success, but failure reasons were of a greater variety. This outcome is reasonable if one remembers that failure tends to be externally attributed, and that there are a great many unique situational exigencies upon which subjects may place attributions.

One of the more interesting aspects of the present study involves a comparison of the results for trait ratings with the attribution ratings. Following Kepka and Brickman's (1971, p. 228) suggestion that ability is a structural concept in the same way that traits are, it would be expected that comparable Success by Drug interactions would be obtained for the traits as was obtained for ability attribution. However, this result did not occur. If anything, the results for traits were more like the results for motivation ratings, in contrast to Kepka and Brickman's suggestion. In fact, an additive model would nicely account for the effects of the two manipulations on both trait and motivation ratings, but not for the results for ability attribution.

It may well be that the traits ratings are best considered as motivational or dynamic ratings. Conventional wisdom views traits as structural concepts, but such concepts as perceptive, ambitious, impulsive, and self-centered seem to have a motivational component as well. If so, then the trait ratings are quite reasonably consistent with the rating of trying.

This line of reasoning suggests that an additive model will account for the integration of motivational information, but not for ability informaton. This conclusion is directly opposed to the results of Kepka and Brickman (1971, p. 227), although it should be kept in mind that they did provide subjects with some ability information (SAT scores) along with outcome information (grades) from which intelligence was inferred. The present study used only outcome information, and subjects had to infer both ability and motivation.

Despite these differences between studies, the lack of an interaction for the motivation measure in the present study along with a significant interaction for ability tends to substantiate Kepka and Brickman's general thesis that in naive psychology motivation and ability are qualitatively different concepts. Following their suggestion and that of Hendrick (1972) ${ }^{2}$ the study of attribution processes and impression formation may both profit if future impression research will use many different types of dependent variables instead of the customary "likability" measure. 


\section{REFERENCES}

Anderson, N. H. Averaging versus adding as a stimulus combination rule in impression formation. Journal of Experimental Psychology, 1965, 70, 394-400.

Asch, S. E. Forming impressions of personality. Journal of Abornormal and Social Psychology, 1946, 41. 258-290.

Feather, N. T., \& Simon, J. G. Attribution of responsibility and valence of outcome in relation to initial confidence and success and failure of self and other. Journal of rersonality and Social Psychology, 1971, 18, 173-188.

Heider, F. The psychology of interpersonal relations. New York: Wiley, 1958 .

Kepka, E. J., \& Brickman, P. Consistency versus discrepancy as clues in the attribution of intelligence and motivation. Journal of Personality and Social Psychology, 1971, 20, 223-229.

McArthur, L. A. The how and what of why: Some determinants and consequences of causal attribution. Journal of Personality and Social Psychology, 1972, 22, 171-193.

Streufert, S., \& Streufert, S. C. Effects of conceptual structure, failure, and success on attribution of causality and interpersonal attitudes. Journal of Personality and Social Psychology, 1969, 11, 138-147.

Weiner, B. Theories of motivation from mechanism to cognition Chicago: Markham, 1972.

Weiner, B., Frieze, I., Kukla, A., Reed, L., Rest, S., \& Rosenbaum, R. M. Perceiving the causes of success and failure. New York: General Learning Press, 1971.
Weiner, B., \& Kukla, A. An attributional analysis of achievement motivation. Joumal of Personality and Social Psychology, $1970,15,1 \cdot 20$.

\section{NOTES}

1. Not all drugs are viewed as external causal sources. An earlier study which used a different scenario described the actor as using "pep" pills. The predicted interactions did not occur. An analysis of subjects' written comments indicated that the drug manipulation failed in the sense that subjects assimilated the use of pep pills directly to the actor's trying, in effect viewing the pills as part of the actor's internal causality. Apparently use of pep pills by college students, particularly at exam time, is so common that students do not view this drug as an external causative agent. LSD as described in the present experiment is of course quite a different matter.

2. Hendrick, C. Effects of stimulus consistency-inconsistency on impressions of personality. Paper presented at meeting of the Midwestern Psychological Association, Cleveland, May 1972. 